\title{
Maternal Depression and Mother-to-Infant Bonding: The Association of Delivery Mode, General Health and Stress Markers
}

\author{
Mihyon Song1, Hiroshi Ishii ${ }^{1}$, Masahiro Toda ${ }^{2}$, Takuji Tomimatsuํㅜ, Hironobu Katsuyama ${ }^{3}$, \\ Yuichiro Nakai ${ }^{1}$, Koichiro Shimoya ${ }^{*}$ \\ ${ }^{1}$ Department of Obstetrics and Gynecology, Kawasaki Medical School, Kurashiki City, Japan \\ ${ }^{2}$ Department of Foods and Human Nutrition, Notre Dame Seishin University, Okayama City, Japan \\ ${ }^{3}$ Department of Public Health, Kawasaki Medical School, Kurashiki City, Japan \\ Email: mihyon0123@gmail.com,gyne@med.kawasaki-m.ac.jp,mt@wakayama-med.ac.jp, tomimatsu@gyne.med.osaka-u.ac.jp, \\ katsu@med.kawasaki-m.ac.jp, pikapika08594693@yahoo.co.jp, *shimoya@med.kawasaki-m.ac.jp
}

How to cite this paper: Song, M., Ishii, H., Toda, M., Tomimatsu, T., Katsuyama, H., Nakai, Y. and Shimoya, K. (2017) Maternal Depression and Mother-to-Infant Bonding: The Association of Delivery Mode, General Health and Stress Markers. Open Journal of Obstetrics and Gynecology, 7, 155-166. https://doi.org/10.4236/ojog.2017.72017

Received: December 5, 2016

Accepted: February 1, 2017

Published: February 4, 2017

Copyright (c) 2017 by authors and Scientific Research Publishing Inc. This work is licensed under the Creative Commons Attribution-NonCommercial International License (CC BY-NC 4.0). http://creativecommons.org/licenses/by-nc/4.0/ (c) (i) (8) Open Access

\begin{abstract}
Aim: The aim of the present study was to examine associations among maternal stress level, general health, mother to infant bonding, maternal depression level, and mode of delivery. Methods: Mothers who delivered a single baby at term were recruited with a total 435 mothers participating in the study. Outcome measures: Data were collected 6 months after delivery using General Health Questionnaire (GHQ-28), Mother-to-Infant Bonding Scale (MIBS), Edinburgh Postnatal Depression Scale (EPDS) as well as socio-demographic and medical information at 6 months. Additionally, salivary cortisol and chromogranin levels were determined. Results. The proportion of breastfeeding mothers in the vaginal delivery group (51.4\%) was significantly higher than that of the cesarean section group (24\%). GHQ-28 scores were significantly related to EPDS scores and MIBS scores $(\mathrm{P}<0.001))$. EPDS scores were also associated with MIBS scores $(\mathrm{P}<0.001))$. However, there was no significant relationship between salivary stress marker levels and other questionnaire scores. MIBS scores of the vaginal delivery group $(1.3 \pm 1.7)$ were significantly better than those of the planned cesarean section group $(2.1 \pm 2.8)$. Multiple regression analysis revealed that maternal age and cesarean section were significantly associated with MIBS and EPDS scores $(\mathrm{P}<0.01)$. Conclusion: Maternal general health is associated with maternal psychological health. These results suggest that the support of maternal health is important to maintain maternal psychological status and bonding to infants. Because EPDS scores were significantly worse in the planned cesarean section group (4.2 \pm 3.3$)$, careful management is needed of mothers who deliver by planned cesarean section.
\end{abstract}




\section{Keywords}

General Health Questionnaire (GHQ-28), Mother-to-Infant Bonding Scale (MIBS), Edinburgh Postnatal Depression Scale (EPDS), Salivary Cortisol, Salivary Chromogranin A

\section{Introduction}

Women's physical and mental health, endocrine secretion, internal and external genitalia, and other circumstances vary during pregnancy and the postpartum period. The puerperium is a high risk period for mental disorders such as maternity blues and postpartum depression [1]. Maternity blues, which happens within 1 week after birth and remits spontaneously within about 3 days, is found in $30 \%-40 \%$ of mothers in Japan, and there is no evidence that this affects mother-to-infant bonding. However, postpartum depression, which develops by 3 months after birth and occurs in approximately $10 \%$ of mothers in Japan [2], is associated with a high frequency (quantity) of maternal negative emotion toward her infant and is likely to precipitate attachment disorder. At 6 weeks post partum, the frequency of postpartum depression is not affected by mode of delivery [3]. However, studies on the association between maternal mental health and delivery mode are limited.

It is well recognized that promoting good mother-child attachment during pregnancy might influence the level of postpartum depression [4]. The relationship between maternal depression and mother to infant bonding is believed to be important for both maternal and neonatal health. Although delivery mode does not affect contact between mother and the newborn child [3], studies on the association between delivery mode and mother-to-infant bonding are also limited.

The potential for mental health problems can be evaluated by assessing stressrelated hormone levels. Evaluation of saliva for levels of physiological stress markers, such as cortisol and catecholamine, is very useful for objectively assessing stress. Salivary cortisol level is often used as a stress index because of various advantages such as a noninvasive collection procedure. Chromogranin A ( $\mathrm{CgA})$ is a reliable marker of a psychological stress response because it reflects mental stress rather than physical stress [5] [6]. Therefore, salivary cortisol concentrations and $\mathrm{CgA}$ /protein levels are useful in determining maternal stress levels. Salivary cortisol and $\mathrm{CgA}$ /protein levels are normally elevated during pregnancy; however, this elevation was suppressed in a chronic high stress group during pregnancy [7].

In Japan several superstitions are believed among individuals of maternal age. Many mothers believe that labor pain brings good motherhood and attachment to the infant. They also believe that a mother's level of satisfaction with delivery affects her postnatal mental health. Those superstitions lack scientific basis, but they affect the behavior of pregnant women such as her choice of a birthing fa- 
cility.

Recently, we reported that delivery mode and episiotomy affect sexual function at 6 months after delivery [8]. In the present study, we analyzed the relationship among maternal health, bonding, depression and stress levels using the same population [8]. The present study aimed to demonstrate relationships among maternal stress levels, general health, mother-to-infant bonding, maternal depression level, and mode of delivery. Salivary stress marker levels were measured, and the relationship among delivery method, postpartum general health, mother-to-infant bonding, and maternal depression level was investigated to improve mothers' quality of life and identify good delivery management practices.

\section{Methods}

\subsection{Procedure}

Mothers who delivered a singleton baby at term at Kawasaki University hospital and related hospitals were recruited for the present study, as has been previously reported [8]. Six months post partum, questionnaires and devices for obtaining saliva samples were sent by mail to mothers who had given informed consent. The responses and saliva samples were analyzed to detect stress levels. The data were collected from November 2011 to June 2013. A total of 435 mothers participated in the study. Examinations were performed between 10:00 a.m. to 11:00 a.m., starting $>2 \mathrm{~h}$ after consumption of the morning meal because food should not be consumed for at least $90 \mathrm{~min}$ before salivary sampling for cortisol level determination [9]. This study was approved by the Ethical Committees of Kawasaki Medical School.

\subsection{Main Outcome Measures}

\subsubsection{General Health Questionnaire (GHQ-28)}

The General Health Questionnaire (GHQ) is a 60-item self-administered screening tool designed to detect nonpsychotic psychiatric illnesses. The GHQ-28, a shorter version of the original GHQ, has been shown to be reliable and valid [10]. The GHQ-28 is used to assess general health problems [11]. It is used in the general population and within communities or non-psychiatric clinical settings such as primary care or general medical outpatient clinics [12].

\subsubsection{Mother-to-Infant Bonding Scale (MIBS)}

The MIBS is a self-report scale composed of 10 items on a 4-point Likert scale (from 0, "not at all" to 3, "very much"). We used the Japanese version of the MIBS to determine the mother-to-infant bonding level [13].

\subsubsection{Edinburgh Postnatal Depression Scale (EPDS)}

The EPDS is a self-report questionnaire composed of ten items scored on a four-point Likert scale $(0-3)$ designed to assess pregnancy and postpartum depression [14]. Numerous studies have used this instrument during the antenatal and/or postpartum period [15] [16]. In the present study we used the Japanese 
version of EPDS, which shows good internal consistency and test-retest reliability [17].

\subsection{Characteristics of the Sample}

A self-report questionnaire on maternal background was administered. We also assessed the mothers' satisfaction level with delivery, scored on a 5-point Likert scale $(0-4)$.

\subsection{Determination of Salivary Cortisol Levels}

Salivette sampling devices (Sarstedt, Rommelsdorf, Germany) were used to collect a sufficient quantity of saliva. The Salivette includes a small cotton swab and stimulates saliva flow to a rate that enables collection of an adequate specimen within $1 \mathrm{~min}$. The samples were transferred at $4^{\circ} \mathrm{C}$, and after centrifugation at $7000 \mathrm{~g}$ for $15 \mathrm{~min}$, saliva was stored at $-80^{\circ} \mathrm{C}$ until determination of salivary cortisol levels with a commercial enzyme immunoassay kit (Enzo Life Sciences, PA, USA). The intra-and inter-assay coefficients of variation (CV) were $<10 \%$.

\subsection{Determination of Salivary CgA Levels}

Salivary CgA levels were determined by ELISA using a previously described method (Tsubouchi) with a YK070 Chromogranin A (human) electro-immunoassay kit (Yanaihara Institute, Shizuoka, Japan); the intra- and inter-assay CVs were $<5 \%$.

\subsection{Statistical Analysis}

Data are reported as mean \pm standard deviation (SD). Statistical significance was assessed using ANOVA and the Wilcoxon signed-rank test with a 5\% significance level. The correlation coefficients between variables were determined by Spearman rank analysis. A multiple regression analysis was undertaken to identify the variables that predicted maternal general and psychological health. The data were analyzed with IBM SPSS statistics ver. 20 (IBM, Armonk, NY, USA).

\section{Results}

We received 435 completed questionnaires and samples of saliva samples. Table 1 presents characteristics of the sample. There were significant differences in the numbers of children and gestational weeks at delivery depending on the mode of delivery. The mean for gestational weeks in the planned cesarean section group $(37.7 \pm 1.12)$ was significantly lower, compared with other delivery modes. The ratios for early neonatal attachment in both the planned and emergent cesarean section groups ( $42.9 \%$ and $44 \%$, respectively) were significantly lower. The breastfeeding ratios for both the vaginal delivery groups with and without oxytocin administration ( $82.6 \%$ and $82.9 \%$, respectively) were significantly higher. The degrees of satisfaction with delivery differed significantly depending on delivery mode with higher satisfaction in the vaginal delivery group compared to others. 
Table 1. Characteristics of the present study.

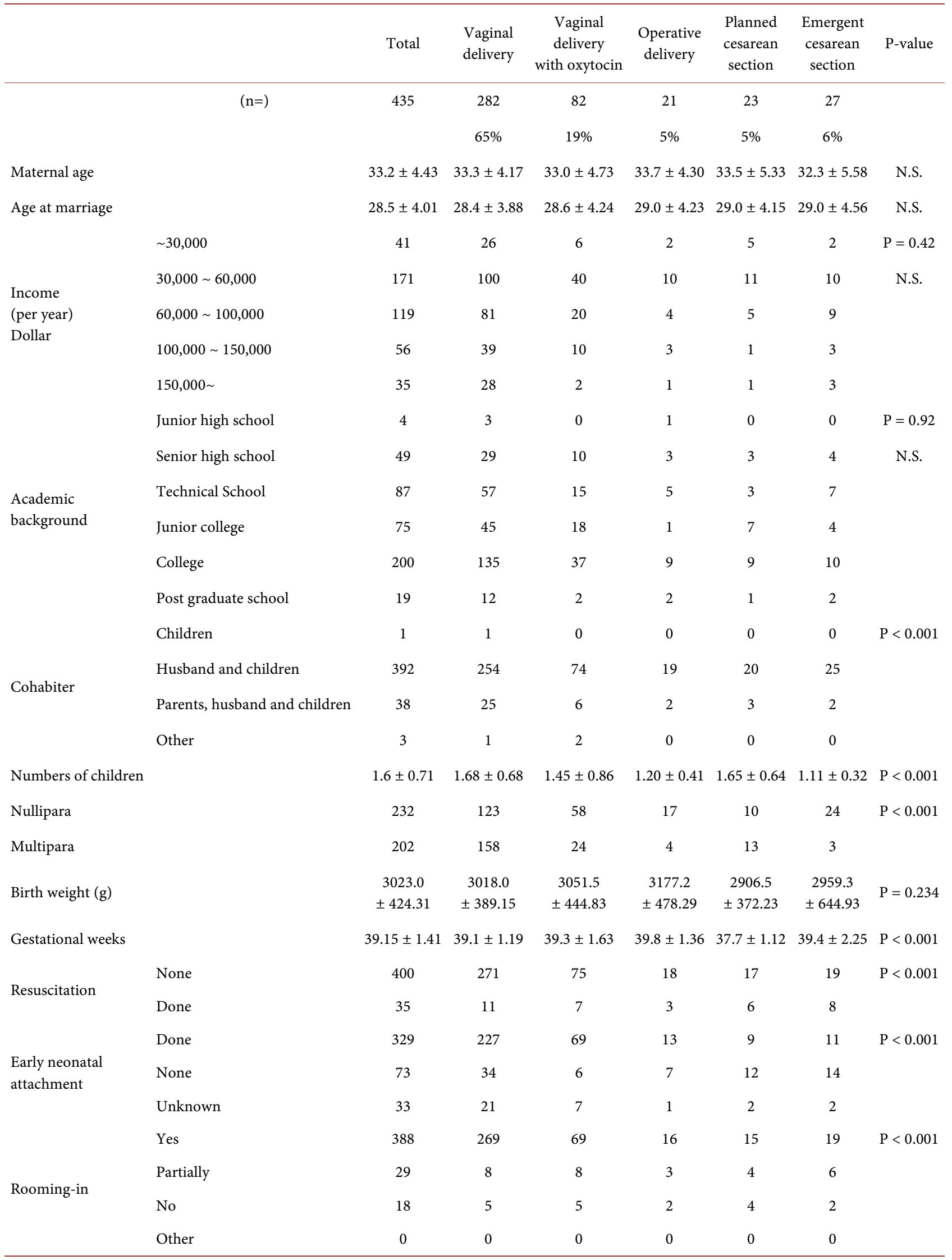




\section{Continued}

\begin{tabular}{|c|c|c|c|c|c|c|c|c|}
\hline & Breastfeeding & 346 & 233 & 68 & 15 & 11 & 19 & $\mathrm{P}<0.001$ \\
\hline \multirow[t]{2}{*}{ Breastfeeding } & Bottle feeding & 7 & 3 & 1 & 0 & 1 & 2 & \\
\hline & Mixed feeding & 82 & 46 & 13 & 6 & 11 & 6 & \\
\hline \multirow{3}{*}{$\begin{array}{l}\text { Attendance of } \\
\text { husband at delivery }\end{array}$} & Yes & 306 & 221 & 60 & 18 & 2 & 5 & $\mathrm{P}<0.001$ \\
\hline & No & 129 & 61 & 22 & 3 & 21 & 22 & \\
\hline & None & 98 & 88 & 10 & 0 & 0 & 0 & not done \\
\hline \multirow[t]{3}{*}{ Laceration } & Episiotomy & 126 & 67 & 41 & 18 & 0 & 0 & \\
\hline & Yes & 160 & 127 & 31 & 2 & 0 & 0 & \\
\hline & Private clinic & 336 & 229 & 62 & 17 & 12 & 16 & $\mathrm{P}<0.001$ \\
\hline \multirow[t]{2}{*}{ Place at delivery } & Hospital & 78 & 36 & 16 & 4 & 11 & 11 & \\
\hline & Midwifery & 21 & 17 & 4 & 0 & 0 & 0 & \\
\hline \multirow{2}{*}{$\begin{array}{l}\text { Complication } \\
\text { during pregnancy }\end{array}$} & Yes & 77 & 34 & 19 & 3 & 12 & 9 & $\mathrm{P}<0.001$ \\
\hline & No & 358 & 248 & 63 & 18 & 11 & 18 & \\
\hline \multirow{5}{*}{$\begin{array}{l}\text { Degree of } \\
\text { satisfaction }\end{array}$} & Very good & 244 & 192 & 36 & 7 & 8 & 1 & $\mathrm{P}<0.001$ \\
\hline & Good & 155 & 81 & 39 & 10 & 10 & 15 & \\
\hline & Average & 12 & 2 & 0 & 2 & 2 & 6 & \\
\hline & Poor & 19 & 5 & 7 & 1 & 3 & 3 & \\
\hline & Very poor & 5 & 2 & 0 & 1 & 0 & 2 & \\
\hline
\end{tabular}

As shown in Table 2, we assessed the relationships among the study factors. A number of children were significantly associated with MIBS scores $(\mathrm{P}<0.001)$. GHQ-28 scores were significantly related with EPDS scores $(\mathrm{P}<0.001)$ and MIBS scores $(\mathrm{P}<0.001)$. EPDS scores were also associated with MIBS scores ( $\mathrm{P}$ $<0.001)$. The levels of chromogranin A/protein in the saliva were significantly associated with the titers of salivary cortisol $(\mathrm{P}<0.001)$. However, no significant relationship was observed between the stress markers in the saliva and other variables, such as GHQ-28, EPDS and MIBS scores.

Table 3 shows the GHQ-28 scores and the titers of salivary stress markers in five groups divided by mode of delivery. There were no significant differences in GHQ28 scores among the 5 groups, nor were there significant differences in salivary stress marker due to the wide distribution. Figure 1 shows that EPDS scores of the vaginal delivery group $(3.3 \pm 3.41)$ were lower than those of the planned cesarean section group $(4.2 \pm 3.29)$, but the difference is not significant. As shown in Figure 1(b), there were significant differences in MIBS between the vaginal delivery group $(1.3 \pm 1.66)$ and the planned cesarean section group $(2.1$ $\pm 2.76)$. Within the cesarean section group, MIBS scores of nullpara mothers tended to be worse than those of multipara mothers $(P=0.07)$. There were no significant differences in EPDS between any groups. 
Table 2. Significance among factors in the present study.

\begin{tabular}{lcccccc}
\hline & $\begin{array}{c}\text { Numbers of } \\
\text { children }\end{array}$ & $\begin{array}{c}\text { GHQ28 } \\
\text { score }\end{array}$ & $\begin{array}{c}\text { EPDS } \\
\text { score }\end{array}$ & $\begin{array}{c}\text { MIBS } \\
\text { score }\end{array}$ & $\begin{array}{c}\text { Salivary } \\
\text { chromogranin A }\end{array}$ & $\begin{array}{c}\text { Salivary } \\
\text { cortisol }\end{array}$ \\
\hline Numbers of children & N.S. & N.S. & 0.001 & N.S. & N.S. \\
GHQ28 score & N.S. & & 0.001 & 0.001 & N.S. & N.S. \\
EPDS score & N.S. & 0.001 & & 0.001 & N.S. & N.S. \\
MIBS score & 0.001 & 0.001 & 0.001 & & N.S. & N.S. \\
Chromogranin A & N.S. & N.S. & N.S. & N.S. & & 0.001 \\
Cortisol & N.S. & N.S. & N.S. & N.S. & 0.001 & \\
\hline
\end{tabular}

Table 3. Association among mode of delivery and results of GHQ-28, MIBS, EPDS, cortisol and CgA.

\begin{tabular}{lccccc}
\hline & $\begin{array}{c}\text { Vaginal } \\
\text { delivery }\end{array}$ & $\begin{array}{c}\text { Vaginal } \\
\text { delivery with } \\
\text { oxytocin }\end{array}$ & $\begin{array}{c}\text { Operative } \\
\text { delivery }\end{array}$ & $\begin{array}{c}\text { Planned } \\
\text { caesarean } \\
\text { section }\end{array}$ & $\begin{array}{c}\text { Emergent } \\
\text { Caesarean } \\
\text { section }\end{array}$ \\
\hline GHQ28 & $47.1 \pm 8.3$ & $48.2 \pm 9.1$ & $50.5 \pm 11.2$ & $49.2 \pm 9.5$ & $48.2 \pm 7.8$ \\
Cortisol $(\mathrm{pg} / \mathrm{ml})$ & $3463 \pm 1258$ & $3472 \pm 1375$ & $3759 \pm 1802$ & $4168 \pm 2243$ & $4731 \pm 6337$ \\
CgA/protein $(\mathrm{pmol} / \mathrm{ng})$ & $18.40 \pm 64.50$ & $17.54 \pm 58.27$ & $6.77 \pm 14.10$ & $2.68 \pm 6.11$ & $4.53 \pm 11.90$ \\
\hline
\end{tabular}

Finally, a multiple regression analysis was performed to identify variables that predict maternal general and psychological health. Maternal age and cesarean section were significant predictors of GHQ28 scores $(\mathrm{P}=0.005$ and $\mathrm{P}=0.015$, respectively), EPDS scores $(\mathrm{P}=0.003$ and $\mathrm{P}=0.032$, respectively), and MIBS scores $(\mathrm{P}=0.007$ and $\mathrm{P}=0.036$, respectively).

\section{Discussion}

The present study analyzed the association between maternal bonding, postpartum depression, and delivery mode. There are several studies associated with maternal bonding, postpartum depression, and delivery mode [18] [19] [20]. As shown in Table 1, there were significant differences in breastfeeding ratios among the different delivery mode groups. The breastfeeding ratio of the vaginal delivery, vaginal delivery with oxytocin, operative delivery, planned cesarean section and emergent cesarean section groups were $74.7 \%$ (145/194), 66.7\% (30/45), 50\% (6/12), $36.8 \%(7 / 19)$ and $38.4 \%$ (5/13), respectively. These results are similar to the previous study in this series [3] [21]. The reason for the low breastfeeding ratio in the cesarean section group is unknown. Breastfeeding mothers showed greater activations in the superior frontal gyrus, insula, precuneus, striatum, and amygdala [20]. Possibly, the low ratio of early neonatal attachment in both planned and emergent cesarean section groups, as well as oxytocin secretion during labor may affect breastfeeding. The degree of satisfaction with delivery in the vaginal delivery group was higher than that of the cesarean section group, and this factor may also affect breastfeeding. 


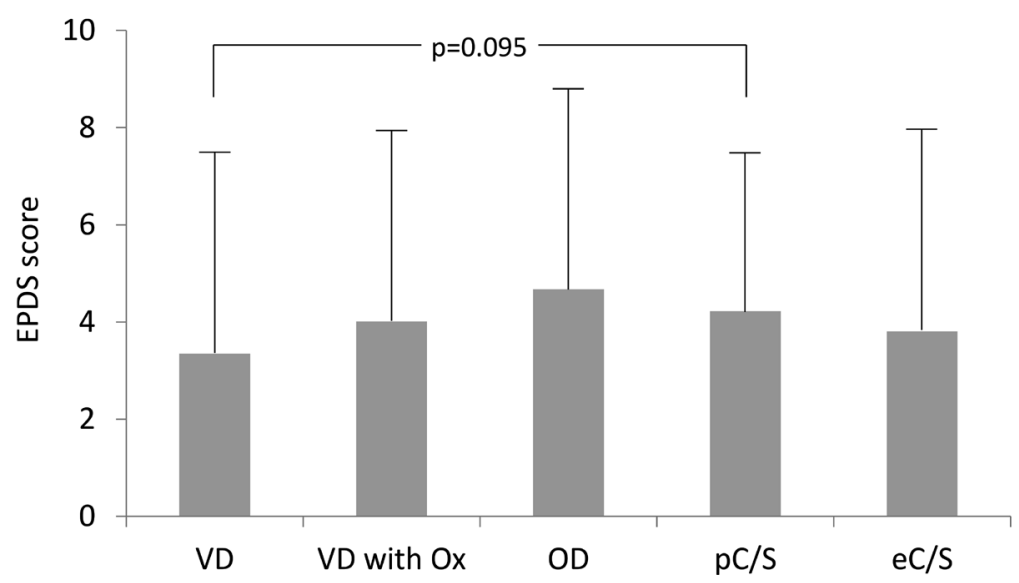

(a)

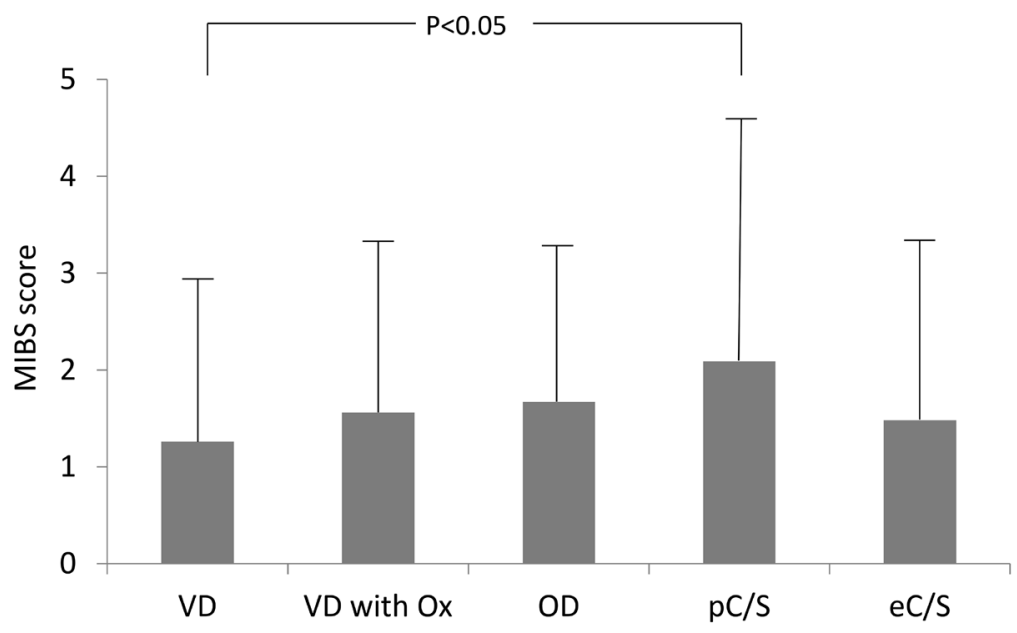

(b)

Figure 1. (a) EPDS score and mode of delivery. (b) MIBS score and mode of delivery. VD: Vaginal delivery group, VD with Ox: Vaginal delivery with oxytocin group, OD: Operative delivery group, pC/S: Planned caesarean section group, eC/S: Emergent cesarean section group.

GHQ-28 scores were significantly related to EPDS scores and MIBS scores. Maternal general health level is associated with maternal psychological health and bonding activity. These results suggest that support of maternal health care is important for maintaining maternal psychological status and bonding to infants. EPDS scores were associated with MIBS score. Yamashita reported the same results in an analysis of 88 mothers [2]. Promoting good mother-child attachment during pregnancy may influence the level of postpartum depression [4]. Several studies have demonstrated the association between maternal depression and MIBS [22] [23] [24]. Our present study supports that maternal depressive status affects mother-to-infant bonding in Japan. The levels of chromogra$\operatorname{nin} \mathrm{A} /$ protein in the saliva were significantly associated with the titers of cortisol in the saliva. Evaluation of physiological stress markers in the saliva is useful method for objectively assessing stress. However, salivary stress markers could not be used to detect maternal general health, postpartum depression and bonding to infants. 
As shown in Figure 1(a), EPDS scores were not associated with mode of delivery. Previous studies have demonstrated that mode of delivery is not associated with postpartum emotional distress [25] [26] [27]. Adams et al. noted that concern for maternal postpartum mental health care should not influence clinical decisions regarding mode of delivery [25]. Our study is consistent with previous studies and supports that maternal health care should be offered independently of mode of delivery. Carlander et al. concluded that mode of delivery does not affect how mothers experience contact with their newborn child [3]. However, Figure 1(b) demonstrates that MPDS scores were significantly worse in the planned cesarean section group. The low breastfeeding ratio might affect MPDS score in cesarean section group. In general, oxytocin acts to allow the high levels of social sensitivity and attunement necessary for human socializing and for rearing a human child [28]. It could be speculated that the level of oxytocin secretion may affect mother-to-infant bonding. However, further investigation would be necessary to determine the association between bonding and mode of delivery. In the cesarean section group MIBS score of nullipara mothers tended to be worse than those of multipara mothers. Intensive care for nullipara mothers may be necessary to promote maternal bonding to her infant.

Multiple regression analysis revealed that maternal age and cesarean section were significantly associated with maternal general and psychological health. Maternal age and cesarean section affected postpartum maternal health. The negative effects of cesarean sections on maternal psychological health should be considered, and further investigations are needed to study the association between maternal psychological health and delivery mode.

\section{Conclusion}

Maternal general health is associated with maternal psychological health. These results suggest that maternal health care is important to maintain maternal psychological health and bonding to infants. Further investigation is needed to determine the association between bonding and mode of delivery.

\section{Acknowledgements}

The authors thank Dr. Kaoru Miyake (Miyake Clinic), Dr. Takeshi Taniguchi (Taniguchi Hospital), and Dr. Harumi Urano (Ikuryo Clinic) for recruiting the participants. This work was supported, in part, by Grants-in-Aid for Scientific Research (Nos. 21592118, 24592493) from the Ministry of Education, Science, and Culture of Japan (Tokyo, Japan), Health Labor Sciences Research Grant of Research on Child and Families (Tokyo, Japan), and Research Project Grant 21411, 25B-14 and 25G-6 from Kawasaki Medical School (Kurashiki, Japan). The authors declare no potential conflicts of interest.

\section{References}

[1] Wisner, K.L., Sit, D.K.Y., Altemus, M., Bogen, D.L., Famy, C.S., Pearlstein, T.B., Misra, D.P., Reynolds, S.K. and Perel, J.M. (2012) Chapter 52: Mental Health and 
Behavioral Disorders in Pregnancy. In: Gabbe, S.G., Niebyl, J.R., Galan, H., Jauniaux, E.R.M., Landon, M., Simpson, J.L. and Driscoll, D., Eds., Obstetrics. Normal and Problem Pregnancies, 6th Edition, Elsevier, Philadelphia, PA, 1158-1188.

[2] Yamashita, H. (2003) Association between Postnatal Depression and Bonding Disorder. Seishinka Shindangaku, 14, 41-48. (In Japanese)

[3] Carlander, A.K., Edman, G., Christensson, K., Andolf, E. and Wiklund, I. (2010) Contact between Mother, Child and Partner and Attitudes towards Breastfeeding in Relation to Mode of Delivery. Sexual \& Reproductive HealthCare, 1, 27-34. https://doi.org/10.1016/j.srhc.2009.10.001

[4] Goecke, T.W., Voigt, F., Faschingbauer, F., Spangler, G., Beckmann, M.W. and Beetz, A. (2012) The Association of Prenatal Attachment and Perinatal Factors with Pre- and Postpartum Depression in First-Time Mothers. Archives of Gynecology and Obstetrics, 286, 309-316. https://doi.org/10.1007/s00404-012-2286-6

[5] Nakane, H., Asami, O., Yamada, Y., Harada, T., Matsui, N., Kannno, T. and Yanaihara, N. (1998) Salivary Chromogranin A as an Index of Psychosomatic Stress Response. Biomedical Research, 19, 401-406. https://doi.org/10.2220/biomedres.19.401

[6] Nakane, H., Asami, O., Yamada, Y. and Ohira, H. (2002) Effect of Negative Air Ions on Computer Operation, Anxiety, and Salivary Chromogranin A-Like Immunoreactivity. International Journal of Psychophysiology, 46, 85-89. https://doi.org/10.1016/S0167-8760(02)00067-3

[7] Tsubouchi, H., Nakai, Y., Toda, M., Morimoto, K., Chang, Y.S., Ushioda, N., Kaku, S., Nakamura, T., Kimura, T. and Shimoya, K. (2011) Change of Salivary Stress Marker Concentrations during Pregnancy: Maternal Depressive Status Suppress Changes of Those Levels. Journal of Obstetrics and Gynaecology Research, 37, 10041009. https://doi.org/10.1111/j.1447-0756.2010.01473.x

[8] Song, M., Ishii, H., Toda, M., Tomimatsu, T., Katsuyama, H., Nakamura, T., Nakai, Y. and Shimoya, K. (2014) Association between Sexual Health and Delivery Mode. Sexual Medicine, 2, 153-158. https://doi.org/10.1002/sm2.46

[9] Toda, M., Morimoto, K., Nagasawa, S. and Kitamura, K. (2004) Effect of Snack Eating on Sensitive Salivary Stress Markers Cortisol and Chromogranin A. Environmental Health and Preventive Medicine, 9, 27-29.

https://doi.org/10.1265/ehpm.9.27

[10] Suda, M., Nakayama, K. and Morimoto, K. (2007) Relationship between Behavioral Lifestyle and Mental Health Status Evaluated Using the GHQ-28 and SDS Questionnaires in Japanese Factory Workers. Industrial Health, 45, 467-473. https://doi.org/10.2486/indhealth.45.467

[11] Goldberg, D.P. and Hillier, V.F. (1979) A Scaled Version of the General Health Questionnaire. Psychological Medicine, 9, 139-145. https://doi.org/10.1017/S0033291700021644

[12] Vallejo, M.A., Jordan, C.M., Diaz, M.I., Comeche, M.I. and Jose, O. (2007) Psychological Assessment via Internet: A Reliability and Validity Study of Online (vs Paper-and-Pencil) Versions of the General Health Questionnaire-28 (GHQ-28) and the Symptoms Check-List-90-Revised (SCL-90-R). Journal of Medical Internet Research, 9, e2. https://doi.org/10.2196/jmir.9.1.e2

[13] Yoshida, K., Yamashita, H., Conroy, S., Marks, M. and Kumar, C. (2012) A Japanese Version of Mother-to-Infant Bonding Scale: Factor Structure, Longitudinal Changes and Links with Maternal Mood during the Early Postnatal Period in Japanese Mothers. Archives of Women's Mental Health, 15, 343-352. https://doi.org/10.1007/s00737-012-0291-1

[14] Cox, J.L., Holden, J.M. and Sagovsky, R. (1987) Detection of Postnatal Depression. 
Development of the 10-Item Edinburgh Postnatal Depression Scale. British Journal of Psychiatry, 150, 782-786. https://doi.org/10.1192/bjp.150.6.782

[15] Dennis, C.L. (2003) The Effect of Peer Support on Postpartum Depression: A Pilot Randomized Controlled Trial. Canadian Journal of Psychiatry, 48, 115-124.

[16] Shrestha, S.D., Pradhan, R., Tran, T.D., Gualano, R.C. and Fisher, J.R. (2016) Reliability and Validity of the Edinburgh Postnatal Depression Scale (EPDS) for Detecting Perinatal Common Mental Disorders (PCMDs) among Women In Low-And Lower-Middle-Income Countries: A Systematic Review. BMC Pregnancy \& Childbirth, 16, 72. https://doi.org/10.1186/s12884-016-0859-2

[17] Tamaki, R., Murata, M. and Okano, T. (1997) Risk Factors for Postpartum Depression in Japan. Psychiatry and Clinical Neurosciences, 51, 93-98. https://doi.org/10.1111/j.1440-1819.1997.tb02368.x

[18] Edhborg, M., Matthiesen, A.S., Lundh, W. and Widström, A.M. (2005) Some Early Indicators for Depressive Symptoms and Bonding 2 Months Postpartum-A Study of New Mothers and Fathers. Archives of Women's Mental Health, 8, 221-231. https://doi.org/10.1007/s00737-005-0097-5

[19] Eisenach, J.C., Pan, P.H., Smiley, R., Lavand'homme, P., Landau, R. and Houle, T.T. (2008) Severity of Acute Pain after Childbirth, but Not Type of Delivery, Predicts Persistent Pain and Postpartum Depression. Pain, 140, 87-94. https://doi.org/10.1016/j.pain.2008.07.011

[20] Kim, P., Feldman, R., Mayes, L.C., Eicher, V., Thompson, N., Leckman, J.F. and Swain, J.E. (2011) Breastfeeding, Brain Activation to Own Infant Cry, and Maternal Sensitivity. Journal of Child Psychology and Psychiatry, 52, 907-915. https://doi.org/10.1111/j.1469-7610.2011.02406.x

[21] Zanardo, V., Svegliado, G., Cavallin, F., Giustardi, A., Cosmi, E., Litta, P. and Trevisanuto, D. (2010) Elective Cesarean Delivery: Does It Have a Negative Effect on Breastfeeding? Birth, 37, 275-279. https://doi.org/10.1111/j.1523-536X.2010.00421.x

[22] Klier, C.M. (2006) Mother-Infant Bonding Disorders in Patients with Postnatal Depression: The Postpartum Bonding Questionnaire in Clinical Practice. Archives of Women's Mental Health, 9, 289-291. https://doi.org/10.1007/s00737-006-0150-z

[23] Moehler, E., Brunner, R., Wiebel, A., Reck, C. and Resch, F. (2006) Maternal Depressive Symptoms in the Postnatal Period Are Associated with Long-Term Impairment of Mother-Child Bonding. Archives of Women's Mental Health, 9, 273 278. https://doi.org/10.1007/s00737-006-0149-5

[24] O'Higgins, M., Roberts, I.S., Glover, V. and Taylor, A. (2013) Mother-Child Bonding at 1 Year. Associations with Symptoms of Postnatal Depression and Bonding in the First Few Weeks. Archives of Women's Mental Health, 16, 381-389. https://doi.org/10.1007/s00737-013-0354-y

[25] Adams, S.S., Eberhard-Gran, M., Sandvik, Å.R. and Eskild, A. (2012) Mode of Delivery and Postpartum Emotional Distress: A Cohort Study of 55,814 Women. BJOG, 119, 298-305. https://doi.org/10.1111/j.1471-0528.2011.03188.x

[26] Goker, A., Yanikkerem, E., Demet, M.M., Dikayak, S., Yildirim, Y. and Koyuncu, F.M. (2012) Postpartum Depression: Is Mode of Delivery a Risk Factor? ISRN Obstetrics and Gynecology, 2012, Article ID: 616759. https://doi.org/10.5402/2012/616759

[27] Sword, W., Landy, C.K., Thabane, L., Watt, S., Krueger, P., Farine, D. and Foster, G. (2011) Is Mode of Delivery Associated with Postpartum Depression at 6 Weeks: A Prospective Cohort Study. BJOG, 118, 966-977. https://doi.org/10.1111/j.1471-0528.2011.02950.x 
[28] Carter, C.S. (2014) Oxytocin Pathways and the Evolution of Human Behavior. Annual Review of Psychology, 65, 17-39.

https://doi.org/10.1146/annurev-psych-010213-115110

Submit or recommend next manuscript to SCIRP and we will provide best service for you:

Accepting pre-submission inquiries through Email, Facebook, LinkedIn, Twitter, etc. A wide selection of journals (inclusive of 9 subjects, more than 200 journals)

Providing 24-hour high-quality service

User-friendly online submission system

Fair and swift peer-review system

Efficient typesetting and proofreading procedure

Display of the result of downloads and visits, as well as the number of cited articles Maximum dissemination of your research work

Submit your manuscript at: http://papersubmission.scirp.org/

Or contact ojog@scirp.org 